Mov Disord. 2009 July 30; 24(10): 1481-1487. doi:10.1002/mds.22621.

\title{
Walking economy in people with Parkinson's disease
}

\author{
Cory L Christiansen, PT, PhD ${ }^{1}$, Margaret L Schenkman, PT, PhD ${ }^{1}$, Kim McFann, PhD ${ }^{2}$,

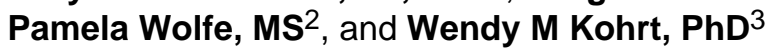 \\ ${ }^{1}$ Department of Physical Medicine \& Rehabilitation, University of Colorado Denver, Aurora, CO \\ ${ }^{2}$ Department of Biostatistics \& Informatics, University of Colorado Denver, Aurora, CO \\ ${ }^{3}$ Division of Geriatric Medicine, University of Colorado Denver, Aurora, CO
}

\begin{abstract}
Gait dysfunction is an early problem identified by patients with Parkinson's disease (PD). Alterations in gait may result in an increase in the energy cost of walking (i.e., walking economy). The purpose of this study was to determine whether walking economy is atypical in patients with PD when compared with healthy controls. A secondary purpose was to evaluate the associations of age, sex, and level of disease severity with walking economy in patients with PD. The rate of oxygen consumption $\left(\mathrm{VO}_{2}\right)$ and other responses to treadmill walking were compared in 90 patients $(64.4 \pm 10.3 \mathrm{yr})$ and 44 controls $(64.6 \pm 7.3 \mathrm{yr})$ at several walking speeds. Pearson correlation coefficients (r) were calculated to determine relationships of age, sex, and disease state with walking economy in PD patients. Walking economy was significantly worse in PD patients than in controls at all speeds above $1.0 \mathrm{mph}$. Across all speeds, $\mathrm{VO}_{2}$ was 6 to $10 \%$ higher in PD patients. Heart rate, minute ventilation, respiratory exchange ratio, and rating of perceived exertion were correspondingly elevated. No significant relationship of age, sex, or UPDRS score with $\mathrm{VO}_{2}$
\end{abstract}

Contact / Corresponding Author: Cory L. Christiansen, PT, PhD Physical Therapy Program, Mailstop C-244 13121 East 17th Avenue, Room 3106 Aurora, CO 80045 cory.christiansen@ucdenver.edu Phone: (303) 724-9101 Fax: (303) 724-9016.

AUTHORS ROLES

Cory L. Christiansen, PT, PhD

1. Research Project: Organization and Execution

2. Statistical Analysis: Review and Critique

3. Manuscript: Writing of the first draft, Review and Critique

Margaret Schenkman, PT, PhD

1. Research Project: Conception, Organization, and Execution

2. Statistical Analysis: Review and Critique

3. Manuscript: Review and Critique

Kim McFann, $\mathrm{PhD}$

1. Statistical Analysis: Design, Execution, Review and Critique

2. Manuscript: Review and Critique

Pamela Wolfe, MS

1. Statistical Analysis: Design, Execution, Review and Critique

2. Manuscript: Review and Critique

Wendy Kohrt, PhD

1. Research Project: Conception, Organization, and Execution

2. Statistical Analysis: Review and Critique

3. Manuscript: Review and Critique 
was found for patients with PD. The findings suggest that the physiologic stress of daily physical activities is increased in patients with early to mid-stage PD, and this may contribute to the elevated level of fatigue that is characteristic of PD.

\section{Keywords}

energy expenditure; gait; Parkinson's disease; walking economy

\section{INTRODUCTION}

Gait dysfunction is a characteristic problem of Parkinson's disease (PD) and one of the earliest functional limitations identified by patients.1 Changes in gait, such as decreased speed, decreased stride rate, and increased variability in stride length are evident in early stages of PD.2, 3 In addition, PD-related gait dysfunction is linked to perceived low quality of life.4, 5

Walking economy, defined as the steady-state aerobic demand for a given submaximal speed of walking,6 is abnormal in some neurological and orthopedic disorders.7 Increased energy expenditure during walking (i.e., poor economy) has been linked to such conditions as stroke8, spinal cord injury9, amputation10, and cerebral palsy.11 In men with PD, there was a trend for the energy cost of cycling to be increased relative to healthy age- and sexmatched controls.12 The finding that energy expenditure was increased during cycling activity led us to the hypothesis that walking economy may also be impaired for patients with PD. If true, interventions targeted to improve economy would be indicated to limit patient fatigue during daily activity. However, to our knowledge, no studies have determined whether the energy cost of walking is increased in patients with PD. Therefore, the purpose of this study was to assess walking economy in patients with PD and healthy individuals of similar age and sex distribution. A secondary purpose was to evaluate the associations of age, sex, and level of disease severity with walking economy in patients with PD.

\section{PATIENTS AND METHODS}

\section{Patients}

The PD patients were participants in a randomized controlled trial of exercise training and functional ability. The current study was focused on walking economy at baseline, before the initiation of the exercise intervention. Healthy, women and men served as controls (HC). The Colorado Multiple Institutional Review Board approved the study, and volunteers provided written informed consent to participate.

PD patients were recruited through local neurology clinics, PD support groups, newspaper advertisements, churches, and word of mouth. Volunteers underwent screening via phone interview, personal interview, neurologist examination, blood testing, and a submaximal graded exercise stress test. Diagnosis of PD was verified by a neurologist using the UK Brain Bank criteria.13 Volunteers in stages 1.5 to 3 using the modified Hoehn and Yahr scale14 were enrolled. Patients were excluded if they had on-state freezing, uncontrolled hypertension, or limited exercise capacity based on musculoskeletal, neuromuscular (other than PD), or cardiovascular disorders.

Control subjects were recruited from the community through newspaper advertisements and word of mouth. Volunteers were recruited with the intent of having a group similar in age (50 to 80 years) and sex to the PD group. Volunteers were excluded if they had limited exercise capacity based on musculoskeletal, neuromuscular, or cardiovascular disorders. 


\section{Walking Economy}

Walking economy was determined by measuring rate of oxygen consumption $\left(\mathrm{VO}_{2}\right)$ by indirect calorimetry (TruMax 2400, ParvoMedics, Sandy, UT) at rest and during treadmill walking at 4 speeds (more in some PD patients), separated by $0.5 \mathrm{mph}$ increments; the range of walking speeds among participants was 0.8 to $4.0 \mathrm{mph}$. After a 5-minute sitting rest period, participants walked for 5 minutes at each of the 4 speeds. For PD patients, the selected speeds were based on the maximum walking speed obtained during the -screening graded exercise test; participants were advanced to additional stages if they felt capable of walking faster. For the HC group, maximum walking speed ranged from 2.5 to $3.5 \mathrm{moh}$, based on individual preference.

Treadmill belt speed was timed near the midpoint of each stage to verify walking speed.Measurements of $\mathrm{VO}_{2}$, rate of carbon dioxide production $\left(\mathrm{VCO}_{2}\right)$, minute ventilation (VE), and respiratory exchange ratio (RER) were recorded every $30 \mathrm{~s}$ and averaged across the last 2 minutes of each stage. Heart rate (HR) was measured using an electronic heart rate monitor (Polar Electro Inc., Lake Success, NY) and averaged across the last 2 minutes of each stage. Participants provided a rating of perceived exertion (RPE)15, using a scale posted in front of the treadmill, at the end of each walking stage.

\section{Factors Associated with Walking Economy}

Age, sex, and level of disease severity were examined as potential covariates of walking economy in the PD group. Score on the Unified Parkinson's Disease Rating Scale (UPDRS)14, 16 (total of Parts I, II, and III) served as the measure of disease severity. The UPDRS was performed by the same trained tester in all participants within one week of the walking economy test.

\section{Statical Analyses}

Because plots of outcome variables suggested normal distributions, no transformations were applied. Baseline characteristics of the two groups were compared by 2-group $t$ tests or likelihood ratio chi square tests for independent proportions, as appropriate. A general linear mixed model approach17 was used to model $\mathrm{VO}_{2}$ curves over time for the two groups. A general linear mixed model with an unstructured covariance matrix and pre-planned contrasts at each stage was used to compare $\mathrm{HC}$ and PD patients on $\mathrm{VO}_{2}, \mathrm{HR}, \mathrm{RER}, \mathrm{VE}$, $\mathrm{VE} / \mathrm{VO}_{2}$, and RPE. Tukey's adjustment was made for multiple comparisons across stage, with level of significance set at $\alpha=0.05$. Pearson correlations were used to compare age and UPDRS score (PD patients only) with $\mathrm{VO}_{2}$ at $2.5 \mathrm{mph}$ for PD patients and healthy controls separately; this speed was selected for its relevance to the question of interest. Sex differences were compared using a 2-group $t$ test. General linear mixed models were used to estimate the association of the pre-determined covariates (age, sex, and UPDRS score) on $\mathrm{VO}_{2}$ over all walking stages.

\section{RESULTS \\ Baseline Characteristics}

PD patients and controls were comparable in age, sex distribution, and anthropometric measures (Table 1). Resting $\mathrm{HR}, \mathrm{VE}$, and $\mathrm{VE} / \mathrm{VO}_{2}$ were significantly higher in PD patients than in controls. The duration of disease in PD patients was 4.8 \pm 4.1 years (mean $\pm \mathrm{SD}$ ). The

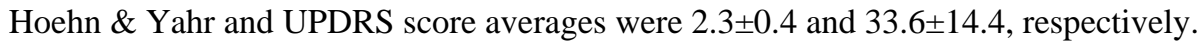




\section{Walking Economy}

As expected, $\mathrm{VO}_{2}$ increased linearly with increasing walking speed in both groups (Figure 1). However, $\mathrm{PD}$ patients had a steeper increase in $\mathrm{VO}_{2}$ than controls across all walking speeds (estimated slope \pm SE; $3.32 \pm 0.07$ versus $2.77 \pm 0.09$, p < 0.001). Even when walking speed was restricted to 1 to $3.5 \mathrm{mph}$ (the range of speeds for which data were available on control subjects), PD patients had a steeper increase in $\mathrm{VO}_{2}(3.37 \pm 0.12$ versus $2.90 \pm 0.16, \mathrm{p}=0.02)$.

Because $\mathrm{VO}_{2}$ curves were not purely linear, a general linear mixed model approach suggested by Cnaan et al.17 was used to model the curves. Using this approach, resting $\mathrm{VO}_{2}$ was the same for the two groups, but $\mathrm{VO}_{2}$ was higher in PD patients than in controls at all walking speeds equal to and greater than $1.5 \mathrm{mph}$ (Table 2).

The analyses described above were conducted using total exercise $\mathrm{VO}_{2}$. The results remained the same when the analyses were conducted using the net increase in $\mathrm{VO}_{2}$ attributable to walking (i.e., $\mathrm{VO}_{2}$ at each stage minus resting $\mathrm{VO}_{2}$ ). Commensurate with the higher $\mathrm{VO}_{2}$ values during walking, other exercise responses (i.e., $\mathrm{HR}, \mathrm{V}_{\mathrm{E}} / \mathrm{VO}_{2}$, RER, and RPE) also tended to be higher in PD patients than in controls (Table 2).

\section{Factors Associated with Walking Economy}

Among PD patients, neither age nor UPDRS was correlated with $\mathrm{VO}_{2}$ at $2.5 \mathrm{mph} ; \mathrm{VO}_{2}$ was not significantly different by sex. Women in the $\mathrm{HC}$ group had lower $\mathrm{VO}_{2}$ values than men (10.8 \pm 0.7 vs. $11.9 \pm 1.6, \mathrm{p}=0.003)$; there was no significant correlation between age and $\mathrm{VO}_{2}$ among controls. Table 3 presents the associations of each covariate with $\mathrm{VO}_{2}$ based on the general linear mixed model for the PD patients.

\section{DISCUSSION}

The major finding of this study was that walking economy was worse in PD patients than in healthy control subjects. The higher $\mathrm{VO}_{2}$ during walking in PD patients was not explained by differences in resting $\mathrm{VO}_{2}$. Commensurate with elevated $\mathrm{VO}_{2}$ during walking, $\mathrm{PD}$ patients also tended to have higher $\mathrm{HR}, \mathrm{V}_{\mathrm{E}} / \mathrm{VO}_{2}$, RER, and RPE responses to exercise than control subjects.

The possibility that energy cost of movement may be adversely influenced by PD has received little attenti on. Protas and colleagues 12 studied 8 men with PD and 7 healthy men during lower-extremity cycling exercise. There were no significant differences in peak aerobic power $\left(\mathrm{VO}_{2} \max \right)$ between the groups, but $\mathrm{PD}$ patients achieved $\mathrm{VO}_{2}$ max at significantly lower power outputs than control subjects. Although the investigators did not provide statistical comparisons of $\mathrm{VO}_{2}$ during submaximal cycling, graphic illustrations of data suggested submaximal $\mathrm{VO}_{2}$ was approximately $15-25 \%$ higher inPD patients than in controls. That observation is consistent with an adverse effect of PD on economy of movement. In a follow-up study, Protas and colleagues 18 confirmed their previous observation that men with PD achieved the same $\mathrm{VO}_{2}$ max as healthy men, but at a lower power output. However, in a small group $(\mathrm{N}=7)$ of female patients, responses were not different from those of control subjects.

To our knowledge, the current study was the first to determine whether walking economy is adversely affected by $\mathrm{PD}$. Our finding that $\mathrm{VO}_{2}$ during walking was higher in both female and male PD patients than in controls across a range of submaximal walking speeds was consistent with the previous observations that men with $\mathrm{PD}$ achieved the same $\mathrm{VO}_{2}$ peak level as controls at a lower power output.12, 18 During walking, PD patients expended from 6 to $10 \%$ more energy than control participants, with increasing disparity at faster walking 
speeds. Thus, patients with PD increase energy expenditure more for a given increase in walking speed than do healthy adults.

Difficulty with walking is experienced by most people with PD.3 Alterations in walking performance, such as increased stride length variability and reduced gait speed, are common even in early stages of the disease.2, 19 The poor gait economy we observed may result from a culmination of changes related to the cardinal PD motor symptoms of tremor, rigidity, hypokinesia, and postural instability. These characteristic motor impairments are present early in the disease process and progress rapidly.20 It is possible that early changes in motor symptoms are reflected by worsened gait economy even when gait function is not dramatically altered.

Tremor, which is most prominent during rest in people with PD, may influence walking economy for people in early stages of PD. The lack of difference in $\mathrm{VO}_{2}$ at rest between the $\mathrm{PD}$ and $\mathrm{HC}$ groups in the current study suggests that tremor did not contribute to the observed differences in the energy cost of walking. However, tremor has been shown in other studies to contribute to increased resting energy expenditure as the disease progresses. Investigations of people with advanced PD symptoms have demonstrated increased resting energy expenditure. 21,22 For example, Markus and colleagues 22 reported resting energy expenditure levels 22\% greater in individuals with PD (Hoehn \& Yahr scores of 3-4; N=11) than control participants. Although data regarding tremor were not presented, energy expenditure was significantly higher when patients were off antiparkinsonian medications. The participants in our study were in relatively early stages of PD and on medication at the time of testing. It is possible that the differences we observed in walking economy between PD patients and controls become even greater with disease progression as a result of tremor.

Although tremor is most common at rest, rigidity, hypokinesia, and postural instability are directly involved during movement. Key predictors of walking economy, such as stride spatiotemporal parameters 23 , can be influenced by these factors. It has been noted that altered regulation of step length is the fundamental deficit in gait hypokinesia24 and reductions in step length occur at early stages of PD.19 Alterations in stride length are known to influence walking economy in healthy individuals.23 Because gait analyses were not performed in the current study, the associations of abnormal gait patterns with walking economy could not be assessed.

Postural instability of PD has been related to increased muscle co-activation.25 Dimitrova and colleagues25 demonstrated that PD patients (Hoehn \& Yahr scores 2.8 \pm 0.3 ) had greater magnitudes of muscle activity during tasks challenging postural stability than healthy control subjects. It has been suggested that increased co-activation of agonist and antagonist muscle groups occurs with aging and can lead to poor walking economy in older adults.26 Thus, it is possible that the increased level of co-activation in people with PD adversely affects walking economy.

A problem related to rigidity and hypokinesia for people with PD is pulmonary dysfunction. 27, 28 PD progression is characterized by decreased upper airway and chest wall compliance.27 In addition, respiratory muscle strength in people with PD has been shown to be significantly less than in age-matched controls.29 For the PD group, $\mathrm{V}_{\mathrm{E}} / \mathrm{VO}_{2}$ tended to be higher than in controls during walking, indicating excess ventilation relative to the level of energy expenditure. It is not clear why ventilation during exercise would be increased in PD patients, but the additional energy required to support higher ventilatory rates could have contributed to the higher $\mathrm{VO}_{2}$ levels during walking in PD patients. However, the differences in $\mathrm{V}_{\mathrm{E}}$ of only 5-6 $\mathrm{L} / \mathrm{min}$ would likely have had only a minimal impact on $\mathrm{VO}_{2}$ $(\sim 0.1 \mathrm{~mL} / \mathrm{min} / \mathrm{kg}) .30$ It has also been shown that pulmonary dysfunction in PD results in 
ventilatory inefficiency (i.e., greater respiratory muscle energy expenditure).28 Thus, factors such as decreased airway and chest wall compliance could increase the work of breathing, thereby increasing the total energy cost of walking.

Along with the factors listed above, other PD-related physiologic impairments may contribute to poor walking economy, including altered mitochondrial and autonomic nervous system functions. Mitochondrial energy production in the substantia nigra is known to be impaired in people with PD.31 If mitochondrial dysfunction is also present in skeletal muscles, which is currently not clearly understood,32 a link to energy expenditure during walking is possible. In addition, autonomic dysfunction33, 34 and, specifically, cardiac sympathetic denervation 35 is present in patients with PD. Changes in cardiovascular responses to exercise have been linked to functional consequences such as shortness of breath and tendency to fatigue during activity.34 Such changes in breathing and level of fatigue may be related to the poor walking economy observed in this study.

Evaluation of age, sex, and level of disease severity in relation to walking economy in patients with PD revealed no significant associations. Based on the PD-related movement disorders discussed above, it was expected that walking economy would be associated with disease severity. However, the expected relationship between UPDRS score, an indicator of disease severity, and $\mathrm{VO}_{2}$ was not statistically significant. Homogeneity of the PD group (restricted to Hoehn and Yahr scale scores of 1.5-3) may have limited the ability to assess this association. In addition, the relatively narrow age range of participants in the study may have limited the ability to assess the influence of age on walking economy.

\section{Limitations}

When interpreting the results of this study, several limitations must be considered. The study was designed to determine whether walking economy is atypical in patients with PD, not to identify underlying mechanisms. Further research will be necessary to understand the role of such factors as rigidity, muscle co-activation, ventilatory dysfunction, muscle mitochondrial function, and autonomic function.

The influence of treadmill compared to overground walking on economy of people with PD is not known. For healthy individuals, kinematic and kinetic measures walking overground compared to on a treadmill are similar.36 However, it is known that people with PD walk with less temporal variability on a treadmill compared to overground.37 If stride variability is related to poor walking economy, the measurement of economy on a treadmill may underestimate the magnitude of the impairment during community walking for people with PD.

Upper extremity activity during economy testing was not controlled in this study. Both HC and PD patients were allowed to use treadmill handrails for support, although they were encouraged to touch the rails only lightly. Frenkel-Toledo and colleagues 23 have previously examined the influence of upper extremity support during overground walking for patients with PD. They found that patients with PD walk with slightly shorter stride lengths, but similar stride variability when comparing upper extremity use (using a walker) to no support. Future examination of controlled upper extremity support will be needed to determine if this is a relatively greater factor for economy of treadmill walking in people with PD compared to healthy individuals.

Finally, among PD patients, $14 \%$ were using negative chronotropic medications and $11 \%$ were using angiotensin converting enzyme inhibitors. Use of cardiac-related medications by HC subjects was not determined. Martin and colleagues 38 examined a group of hypertensive men and demonstrated no difference between placebo and treatment groups in submaximal 
$\mathrm{VO}_{2}$ after short term use of beta-blocker medications. However, there is evidence that long term use of such medications may influence metabolic responses during walking.39, 40 For example; Witte and colleagues 40 studied individuals with congestive heart failure and found 12 months of beta-blocker usage to be linked to decreased submaximal $\mathrm{VO}_{2}$ during treadmill walking. In our study, differences in walking economy between groups may have been minimized if more PD patients than controls were using negative chronotropic medications. Future research should account for the influence of cardiac medications.

\section{Clinical Implications}

The major finding of this study was that patients with PD have poor walking economy when compared to similarly aged healthy adults. Although maximal aerobic power $\left(\mathrm{VO}_{2} \mathrm{max}\right)$ was not measured, previous studies have demonstrated that $\mathrm{VO}_{2} \max$ is normal in patients with PD.12, 18 If true, the impairment in walking economy means that relative intensity of walking (i.e., percent of $\mathrm{VO}_{2} \max$ ) is higher for PD patients than for controls and could contribute to excess fatigue. Our findings suggest a need for targeted interventions to improve walking economy and decrease PD-related movement dysfunction. The clinical importance of movement economy in PD is indirectly supported by several studies demonstrating aerobic exercise benefit for people with PD.5, 41-45 Building from this study, future work should evaluate mechanisms related to poorer walking economy and the response of walking economy to various interventions.

\section{Acknowledgments}

Financial Disclosure: We acknowledge the financial support of NIH (Protocol: \# 1 R01 HD043770) for this study.

\section{REFERENCES}

1. Shulman LM, Gruber-Baldini AL, Anderson KE, et al. The evolution of disability in Parkinson disease. Mov Disord. 2008; 23(6):790-796. [PubMed: 18361474]

2. Carpinella I, Crenna P, Calabrese E, et al. Locomotor function in the early stage of Parkinson's disease. IEEE Trans Neural Syst Rehabil Eng. 2007; 15(4):543-551. [PubMed: 18198712]

3. Morris ME. Movement disorders in people with Parkinson disease: a model for physical therapy. Phys Ther. 2000; 80(6):578-597. [PubMed: 10842411]

4. Marras C, McDermott MP, Rochon PA, Tanner CM, Naglie G, Lang AE. Predictors of deterioration in health-related quality of life in Parkinson's disease: results from the DATATOP trial. Mov Disord. 2008; 23(5):653-659. quiz 776. [PubMed: 18076084]

5. Goodwin VA, Richards SH, Taylor RS, Taylor AH, Campbell JL. The effectiveness of exercise interventions for people with Parkinson's disease: a systematic review and meta-analysis. Mov Disord. 2008; 23(5):631-640. [PubMed: 18181210]

6. Martin PE, Heise GD, Morgan DW. Interrelationships between mechanical power, energy transfers, and walking and running economy. Med Sci Sports Exerc. 1993; 25(4):508-515. [PubMed: 8479306]

7. Waters RL, Mulroy S. The energy expenditure of normal and pathologic gait. Gait Posture. 1999; 9(3):207-231. [PubMed: 10575082]

8. Platts MM, Rafferty D, Paul L. Metabolic cost of over ground gait in younger stroke patients and healthy controls. Med Sci Sports Exerc. 2006; 38(6):1041-1046. [PubMed: 16775542]

9. Teixeira da Cunha-Filho I, Henson H, Qureshy H, Williams AL, Holmes SA, Protas EJ. Differential responses to measures of gait performance among healthy and neurologically impaired individuals. Arch Phys Med Rehabil. 2003; 84(12):1774-1779. [PubMed: 14669182]

10. Detrembleur C, Vanmarsenille JM, De Cuyper F, Dierick F. Relationship between energy cost, gait speed, vertical displacement of centre of body mass and efficiency of pendulum-like mechanism in unilateral amputee gait. Gait Posture. 2005; 21(3):333-340. [PubMed: 15760750] 
11. van den Hecke A, Malghem C, Renders A, Detrembleur C, Palumbo S, Lejeune TM. Mechanical work, energetic cost, and gait efficiency in children with cerebral palsy. J Pediatr Orthop. 2007; 27(6):643-647. [PubMed: 17717464]

12. Protas EJ, Stanley RK, Jankovic J, MacNeill B. Cardiovascular and metabolic responses to upperand lower-extremity exercise in men with idiopathic Parkinson's disease. Phys Ther. 1996; 76(1): 34-40. [PubMed: 8545491]

13. Daniel SE, Lees AJ. Parkinson's Disease Society Brain Bank, London: overview and research. J Neural Transm Suppl. 1993; 39:165-172. [PubMed: 8360656]

14. Fahn, S.; Elton, RL.; Committee, UD. Unified Parkinson's Disease Rating Scale. In: Fahn, S.; Marsden, CD.; Calne, D.; Goldstein, M., editors. Recent Developments in Parkinson's Disease. Macmillan Healthcare Information; Florham Park, NJ: 1987. p. 153-163.

15. Borg G. Psychological basis of perceived exertion. Med Sci Sports Exerc. 1982; 14:377-381. [PubMed: 7154893]

16. The Unified Parkinson's Disease Rating Scale (UPDRS): status and recommendations. Mov Disord. 2003; 18(7):738-750. [PubMed: 12815652]

17. Cnaan A, Laird NM, Slasor P. Tutorial in biostatistics, using the general linear model to analyze unbalances repeated measures and longitudinal data. Stat Med. 1997; 16:2349-2380. [PubMed: 9351170]

18. Stanley RK, Protas EJ, Jankovic J. Exercise performance in those having Parkinson's disease and healthy normals. Med Sci Sports Exerc. 1999; 31(6):761-766. [PubMed: 10378900]

19. Baltadjieva R, Giladi N, Gruendlinger L, Peretz C, Hausdorff JM. Marked alterations in the gait timing and rhythmicity of patients with de novo Parkinson's disease. Eur J Neurosci. 2006; 24(6): 1815-1820. [PubMed: 17004944]

20. Poewe W. The natural history of Parkinson's disease. J Neurol. 2006; 253(Suppl 7):VII2-6. [PubMed: 17131223]

21. Levi S, Cox M, Lugon M, Hodkinson M, Tomkins A. Increased energy expenditure in Parkinson's disease. Bmj. 1990; 301(6763):1256-1257. [PubMed: 2271826]

22. Markus HS, Cox M, Tomkins AM. Raised resting energy expenditure in Parkinson's disease and its relationship to muscle rigidity. Clin Sci (Lond). 1992; 83(2):199-204. [PubMed: 1327636]

23. Martin PE, Morgan DW. Biomechanical considerations for economical walking and running. Med Sci Sports Exerc. 1992; 24(4):467-474. [PubMed: 1560745]

24. Morris ME, Iansek R, Matyas TA, Summers JJ. The pathogenesis of gait hypokinesia in Parkinson's disease. Brain. 1994; 117(Pt 5):1169-1181. [PubMed: 7953597]

25. Dimitrova D, Horak FB, Nutt JG. Postural muscle responses to multidirectional translations in patients with Parkinson's disease. J Neurophysiol. 2004; 91(1):489-501. [PubMed: 12944541]

26. Malatesta D, Simar D, Dauvilliers Y, et al. Energy cost of walking and gait instability in healthy 65- and 80-yr-olds. J Appl Physiol. 2003; 95(6):2248-2256. [PubMed: 12882986]

27. Shill H, Stacy M. Respiratory complications of Parkinson's disease. Semin Respir Crit Care Med. 2002; 23(3):261-265. [PubMed: 16088618]

28. Tzelepis GE, McCool FD, Friedman JH, Hoppin FG Jr. Respiratory muscle dysfunction in Parkinson's disease. Am Rev Respir Dis. 1988; 138(2):266-271. [PubMed: 3195826]

29. Haas BM, Trew M, Castle PC. Effects of respiratory muscle weakness on daily living function, quality of life, activity levels, and exercise capacity in mild to moderate Parkinson's disease. Am J Phys Med Rehabil. 2004; 83(8):601-607. [PubMed: 15277961]

30. Cibella F, Cuttitta G, Romano S, Grassi B, Bonsignore G, Milic-Emili J. Respiratory energetics during exercise at high altitude. J Appl Physiol. 1999; 86(6):1785-1792. [PubMed: 10368338]

31. Mortiboys HJ, Schaefer J, Reichmann H, Jackson S. Mitochondrial dysfunction in Parkinson's disease--revisited. Neurol Neurochir Pol. 2007; 41(2):150-159. [PubMed: 17530578]

32. Kosel S, Hofhaus G, Maassen A, Vieregge P, Graeber MB. Role of mitochondria in Parkinson disease. Biol Chem. 1999; 380(7-8):865-870. [PubMed: 10494835]

33. Jost WH. Autonomic dysfunctions in idiopathic Parkinson's disease. J Neurol. 2003; 250(Suppl 1):I28-30. [PubMed: 12761632] 
34. Goldstein DS. Dysautonomia in Parkinson's disease: neurocardiological abnormalities. Lancet Neurol. 2003; 2(11):669-676. [PubMed: 14572735]

35. Goldstein DS, Holmes C, Li ST, Bruce S, Metman LV, Cannon RO 3rd. Cardiac sympathetic denervation in Parkinson disease. Ann Intern Med. 2000; 133(5):338-347. [PubMed: 10979878]

36. Riley PO, Paolini G, Della Croce U, Paylo KW, Kerrigan DC. A kinematic and kinetic comparison of overground and treadmill walking in healthy subjects. Gait Posture. 2007; 26(1):17-24. [PubMed: 16905322]

37. Frenkel-Toledo S, Giladi N, Peretz C, Herman T, Gruendlinger L, Hausdorff JM. Treadmill walking as an external pacemaker to improve gait rhythm and stability in Parkinson's disease. Mov Disord. 2005; 20(9):1109-1114. [PubMed: 15929090]

38. Martin NB, Broeder CE, Thomas EL, et al. Comparison of the effects of pindolol and propranolol on exercise performance in young men with systemic hypertension. Am J Cardiol. 1989; 64(5): 343-347. [PubMed: 2756879]

39. Wolk R, Johnson BD, Somers VK, et al. Effects of beta-blocker therapy on ventilatory responses to exercise in patients with heart failure. J Card Fail. 2005; 11(5):333-339. [PubMed: 15948082]

40. Witte KK, Thackray S, Nikitin NP, Cleland JG, Clark AL. The effects of long-term beta-blockade on the ventilatory responses to exercise in chronic heart failure. Eur J Heart Fail. 2005; 7(4):612617. [PubMed: 15921802]

41. Herman T, Giladi N, Gruendlinger L, Hausdorff JM. Six weeks of intensive treadmill training improves gait and quality of life in patients with Parkinson's disease: a pilot study. Arch Phys Med Rehabil. 2007; 88(9):1154-1158. [PubMed: 17826461]

42. Burini D, Farabollini B, Iacucci S, et al. A randomised controlled cross-over trial of aerobic training versus Qigong in advanced Parkinson's disease. Eura Medicophys. 2006; 42(3):231-238. [PubMed: 17039221]

43. Miyai I, Fujimoto Y, Yamamoto H, et al. Long-term effect of body weight-supported treadmill training in Parkinson's disease: a randomized controlled trial. Arch Phys Med Rehabil. 2002; 83(10):1370-1373. [PubMed: 12370870]

44. Schenkman M, Hall D, Kumar R, Kohrt WM. Endurance exercise training to improve economy of movement of people with Parkinson disease: three case reports. Phys Ther. 2008; 88(1):63-76. [PubMed: 17940108]

45. Bergen JL, Toole T, Elliott RG 3rd, Wallace B, Robinson K, Maitland CG. Aerobic exercise intervention improves aerobic capacity and movement initiation in Parkinson's disease patients. NeuroRehabilitation. 2002; 17(2):161-168. [PubMed: 12082243] 


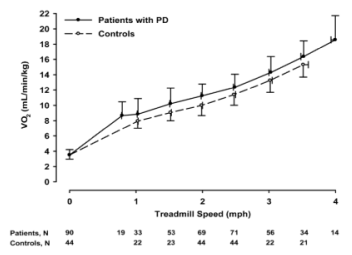

Figure 1.

Relationship between rate of oxygen consumption $\left(\mathrm{VO}_{2}\right)$ and speed of treadmill walking Values below the graph indicate the number of participants from each group who walked at each speed. $\mathrm{VO}_{2}$, rate of oxygen consumption; PD, Parkinson's disease. 


\section{Table 1}

Baseline and resting metabolic characteristics of healthy controls (HC) and patients with Parkinson's disease (PD)

\begin{tabular}{lccc}
\hline Variable & HC $(\mathbf{N}=\mathbf{4 4})$ & PD $(\mathbf{N}=\mathbf{9 0})$ & $p$-value \\
\hline Age (years) & $64.6 \pm 7.3$ & $64.4 \pm 10.3$ & 0.9174 \\
Sex $(\%$ male $)$ & $24 / 44(54.6 \%)$ & $60 / 90(66.7 \%)$ & 0.1731 \\
Height $(\mathrm{cm})$ & $171.9 \pm 10.1$ & $173.2 \pm 9.3$ & 0.4860 \\
Body mass $(\mathrm{kg})$ & $77.2 \pm 12.9$ & $79.6 \pm 16.1$ & 0.3790 \\
$\mathrm{VO}_{2}(\mathrm{~mL} / \mathrm{min} / \mathrm{kg})$ & $3.5 \pm 0.5$ & $3.5 \pm 0.7$ & 0.9662 \\
$\mathrm{Heart} \mathrm{rate}(\mathrm{beat} / \mathrm{min})$ & $68 \pm 10$ & $73 \pm 11$ & 0.0049 \\
$\mathrm{RER}$ & $0.85 \pm 0.10$ & $0.86 \pm 0.11$ & 0.6737 \\
$\mathrm{VE}(\mathrm{L} / \mathrm{min})$ & $10.4 \pm 2.7$ & $11.8 \pm 2.8$ & 0.0083 \\
$\mathrm{VE} / \mathrm{VO}_{2}$ & $32.3 \pm 6.0$ & $36.2 \pm 8.0$ & 0.0045 \\
\hline
\end{tabular}

Data are mean $\pm \mathrm{SD}$, except for sex.

$\mathrm{VO}_{2}$, resting oxygen consumption; RER, respiratory exchange ration; $\mathrm{VE}$, pulmonary minute ventilation; $\mathrm{VE} / \mathrm{VO}_{2}$, ventilatory equivalent 


\section{Table 2}

Between group comparison at each speed from repeated measures analysis of primary and secondary outcome variables*

\begin{tabular}{|c|c|c|c|c|}
\hline Variable & Gait Speed (mph) & $\mathrm{HC}$ & PD & $p$-value ${ }^{\dagger}$ \\
\hline \multirow[t]{6}{*}{$\mathrm{VO}_{2}(\mathrm{ml} / \mathrm{min} / \mathrm{kg})$} & 1.0 & $8.1 \pm 0.3$ & $8.6 \pm 0.2$ & 0.1551 \\
\hline & 1.5 & $9.1 \pm 0.3$ & $9.8 \pm 0.2$ & 0.0266 \\
\hline & 2.0 & $10.0 \pm 0.3$ & $11.0 \pm 0.2$ & 0.0011 \\
\hline & 2.5 & $11.4 \pm 0.3$ & $12.4 \pm 0.2$ & 0.0037 \\
\hline & 3.0 & $13.2 \pm 0.3$ & $14.4 \pm 0.2$ & 0.0036 \\
\hline & 3.5 & $15.3 \pm 0.4$ & $16.7 \pm 0.3$ & 0.0061 \\
\hline \multirow[t]{6}{*}{ Heart Rate (beats/min) } & 1.0 & $80 \pm 2$ & $86 \pm 1$ & 0.0176 \\
\hline & 1.5 & $82 \pm 2$ & $89 \pm 1$ & 0.0129 \\
\hline & 2.0 & $85 \pm 2$ & $92 \pm 1$ & 0.0036 \\
\hline & 2.5 & $90 \pm 2$ & $98 \pm 1$ & 0.0013 \\
\hline & 3.0 & $98 \pm 2$ & $104 \pm 2$ & 0.0218 \\
\hline & 3.5 & $106 \pm 3$ & $115 \pm 2$ & 0.0088 \\
\hline \multirow[t]{6}{*}{ RER } & 1.0 & $0.77 \pm 0.01$ & $0.79 \pm 0.01$ & 0.1614 \\
\hline & 1.5 & $0.82 \pm 0.01$ & $0.83 \pm 0.01$ & 0.3779 \\
\hline & 2.0 & $0.83 \pm 0.01$ & $0.86 \pm 0.01$ & 0.0318 \\
\hline & 2.5 & $0.85 \pm 0.01$ & $0.88 \pm 0.01$ & 0.0033 \\
\hline & 3.0 & $0.87 \pm 0.01$ & $0.90 \pm 0.01$ & 0.0052 \\
\hline & 3.5 & $0.89 \pm 0.01$ & $0.93 \pm 0.01$ & 0.0005 \\
\hline \multirow[t]{6}{*}{$\mathrm{VE}(\mathrm{L} / \mathrm{min})$} & 1.0 & $17.8 \pm 0.9$ & $21.1 \pm 0.7$ & 0.0045 \\
\hline & 1.5 & $21.1 \pm 0.9$ & $24.1 \pm 0.6$ & 0.0065 \\
\hline & 2.0 & $22.8 \pm 1.0$ & $27.0 \pm 0.7$ & 0.0006 \\
\hline & 2.5 & $26.1 \pm 1.1$ & $31.0 \pm 0.8$ & 0.0005 \\
\hline & 3.0 & $30.3 \pm 1.5$ & $36.8 \pm 0.9$ & 0.0002 \\
\hline & 3.5 & $35.7 \pm 1.8$ & $43.5 \pm 1.2$ & 0.0005 \\
\hline \multirow[t]{2}{*}{$\mathrm{VE} / \mathrm{VO}_{2}$} & 1.0 & $24.3 \pm 0.7$ & $26.3 \pm 0.5$ & 0.0201 \\
\hline & 1.5 & $25.2 \pm 0.6$ & $26.5 \pm 0.4$ & 0.0956 \\
\hline
\end{tabular}




\begin{tabular}{lcccc}
\hline Variable & Gait Speed $(\mathbf{m p h})$ & HC & PD & $\boldsymbol{p}_{\text {-value }}{ }^{\dagger}$ \\
\hline & 2.0 & $25.0 \pm 0.6$ & $26.6 \pm 0.4$ & 0.0253 \\
\cline { 2 - 5 } & 2.5 & $24.9 \pm 0.6$ & $26.6 \pm 0.3$ & 0.0141 \\
\hline & 3.0 & $25.0 \pm 0.6$ & $27.0 \pm 0.4$ & 0.0059 \\
\hline RPE & 3.5 & $25.5 \pm 0.6$ & $27.6 \pm 0.4$ & 0.0050 \\
\hline & 1.0 & $0.8 \pm 0.2$ & $0.8 \pm 0.2$ & 0.9565 \\
\hline & 1.5 & $1.1 \pm 0.2$ & $1.4 \pm 0.1$ & 0.1893 \\
\hline 2.0 & $1.5 \pm 0.2$ & $2.0 \pm 0.1$ & 0.0359 \\
\hline 3.0 & $2.0 \pm 0.2$ & $2.7 \pm 0.2$ & 0.0112 \\
\hline 3.5 & $3.4 \pm 0.3$ & $4.4 \pm 0.2$ & 0.0013 \\
\hline
\end{tabular}

* Data shown are means \pm SD unless otherwise stated.

${ }^{\dagger}$ The $p$-values reflect Tukey's adjustment for multiple comparisons across stage. $\mathrm{VO}_{2}$, rate of oxygen consumption; RER, respiratory exchange ration; $\mathrm{VE}$, minute ventilation; $\mathrm{VE} / \mathrm{VO}_{2}$, ventilatory equivalent ratio for oxygen; $\mathrm{RPE}$, rating of perceived exertion. 


\section{Table 3}

Regression of $\mathrm{VO}_{2} / \mathrm{kg}$ on age, sex, UPDRS score controlling for stage (speed) in a linear mixed model

\begin{tabular}{lccc}
\hline Effect & $\boldsymbol{\beta}$ estimate & SE & $\boldsymbol{p}$-value \\
\hline Age & 0.03 & 0.02 & 0.13 \\
Female & 0.46 & 0.37 & 0.22 \\
UPDRS & 0.02 & 0.01 & 0.14 \\
Stage & 3.68 & 0.05 & $<.0001$ \\
\hline
\end{tabular}

UPDRS, Unified Parkinson's Disease Rating Scale. 